\title{
PRÁTICA DOCENTE EM ESCOLAS PARTICULARES DE SANTA MARIA: REALIDADES E DESAFIOS DA EDUCAÇÃO AMBIENTAL
}

\author{
Alessandra Fernandes Wernz ${ }^{1}$, Marcelo Barcellos da Rosa ${ }^{2}$, \\ Jorge Orlando Cuéllar Noguera², Paulo Romeu Machado \\ ${ }^{1}$ Especialista em Educação Ambiental (UFSM) \\ 2 Professores do Curso de Educação Ambiental da UFSM
}

\section{RESUMO}

A educação ambiental tornou-se tema de grande relevância na sociedade contemporânea diante das incontáveis catástrofes que cotidianamente são apresentadas pelos meios de comunicação. Falar em educação ambiental significa repensar as relações do homem, consigo, com os outros e com o meio natural. Nesse processo, a educação formal realizada nas instituições de ensino público e particular é colocada diante de mais um tema de grande importância, por isso, trabalhar com educação ambiental nas escolas constitui um desafio para os educadores. A fim de se identificar a presença da educação ambiental, sua conceituação e seus aspectos positivos e negativos na prática docente em escolas particulares de Santa Maria - RS, uma pesquisa de campo envolvendo professores que atuam nas series iniciais do ensino fundamental foi realizada. Esta consistiu $n$ aplicação de um questionário visando diagnosticar como o trabalho em educação ambiental tem sido desenvolvido. Questionamentos sobre o grau de entendimento, o tipo de atividades desenvoldidas, como as atividades são preparadas são algumas questões que indicam que a Educação ambiental precisa ser compreendida, pensada e repensada pelos educadores, para que possa ir além da conscientização e seja capaz de provocar as transformações necessárias para a modificação da atual realidade, de crise socioambiental. Embora esteja presente em sala de aula, a Educação ambiental ainda é desenvolvida de forma descontinua e fragmentada, não caracterizando, efetivamente como um tema transversal, como sugerem os documentos.

Palavras-chave: educação ambiental, docente, desafio

\section{ABSTRACT}

The environmental education is a topic of great relevance in contemporary society due the countless day disasters that are presented by the media. Speaking in terms of environmental education means rethinking the relationships of man with himself, with others and the natural environment. In that case, formal education in educational institutions held in private and public is put before another issue of great importance. Therefore, to work the environmental education in schools is a challenge for the educators. In order to identify the presence of environmental education, its concept and its strengths and weaknesses in teaching in private schools from Santa Maria - RS, south of Brazil, a field research involving teachers working in elementary education series is reported. In this work, a questionnaire aiming to do a diagnostic as the environmental education has been worked with children was performed. Questions about the understanding level, the type of development of activities, such activities are prepared are some questions that indicate that environmental education needs to be understood, thought and rethought by 


\section{WERNZ et al., vol.(1), n¹, p. $35-45,2010$

educators, so it can be capable of causing the transformations necessary to change present reality of socio-environmental crisis. Although present in the classroom, the environmental education still is developed discontinuous, fragmented and not characterizing effectively as a crosscutting theme, as the official Brazilian documents suggest.

\section{INTRODUÇÃO}

A evolução histórica da humanidade mostra que a relação do homem ocidental com o ambiente vem modificando-se drasticamente ao longo do tempo.

O período medieval caracterizou-se pela percepção do meio ambiente como uma fonte de recursos sem limites de exploração e onde o homem considerava-se o "senhor deste mundo" principalmente pelo predomínio da filosofia cristã.

$\mathrm{Na}$ modernidade, o homem começa a relacionar-se com o meio de maneira racional, teórico-instrumental, onde o conhecimento científico e o crescente desenvolvimento técnico permitiram a utilização destes recursos de forma desordenada, deixando como perspectiva futura, a exaustão destes recursos.

Cresce, então, a partir dos anos 60 a preocupação com a preservação do meio ambiente e com uma nova relação com a natureza. Relação esta, relegada mais ao plano ecológico e em suas dimensões científicas e políticas, contudo ainda superficial do ponto de vista educacional.

É na década de noventa que as questões ambientais ganham maior destaque, introduzindo, inclusive, a educação ambiental como pauta. Realizam-se vários eventos, na busca da conscientização para a necessidade de uma mudança efetiva.

Foi o caso da Conferência das Nações Unidas sobre Meio Ambiente e Desenvolvimento, realizada em junho de 1992 na cidade do Rio de Janeiro, está ficou conhecida como Eco-92, a qual, ainda que tardiamente, representou uma resposta às políticas de muitos países adotadas até então. Desta conferência resultaram alguns compromissos como a realização de convenções sobre clima e biodiversidade, além da Agenda 21, que é um instrumento de orientação e discussão sobre o desenvolvimento mundial, nacional e local, destacando a importância de se desenvolver ações para a inclusão social, de sustentabilidade dos sistemas de produção, a ética, a preservação dos recursos naturais com vistas a se alcançar um desenvolvimento sustentável.

Outro marco importante da Eco-92 foi a realização de um encontro paralelo que reuniu organizações não governamentais e movimentos sociais que discutiram diversos temas e elaboraram 36 tratados. Um deles, conhecido como Tratado de Educação Ambiental (EA) para Sociedades Sustentáveis e Responsabilidade Global. Este serviu de inspiração para a Política Nacional de Educação Ambiental.

Deste modo, é evidente a necessidade de se romper com a relação capitalista que vigora na sociedade atual, gerando uma mudança de paradigma, a qual passa também por uma mudança de hábitos de consumo. Hoje se sabe que o homem não é senhor da natureza. Ao contrário, somos parte dela, apenas usufruímos de uma posição privilegiada.

A percepção de que somente por meio de uma mudança de valores na relação do homem com o meio é que se reforça a necessidade da educação, como essencial para a formação de cidadãos conscientes e com atitudes de respeito em relação com o ambiente.

Portanto, as mudanças nos rumos do planeta passam primordialmente pela educação ambiental, logo, está nas mãos dos educadores que, dentre tantas responsabilidades já atribuídas 


\section{WERNZ et al., vol.(1), n¹, p. $35-45,2010$

ISSN:

pela sociedade, têm mais uma árdua tarefa, serem educadores ambientais, com a função de contribuir para que as mudanças se efetivem na relação homem/sociedade/meio ambiente.

Modificar a realidade que todo o dia nos é apresentada pelos meios de comunicação é um desejo de muitos educadores, mais do que isso, passou a ser uma necessidade. Mas, requer que haja uma gradual e permanente mudança de hábitos, de atitudes, onde todos precisam contribuir com a sua parcela, o que exige muito de todos os atores envolvidos neste processo.

Dessa forma, desenvolver ações encadeadas que produzam resultados efetivos torna-se imprescindível a médio e longo prazo. Assim, a formação de educadores ambientais que possam promover a educação ambiental, contribuindo para que esse processo seja efetivo, é essencial. Neste sentido, toda contribuição é importante, mas acima de tudo, ações que sensibilizem as pessoas, levando-as a mudar de atitude em relação ao meio ambiente, têm seu princípio na formação destes educadores capacitados, sensibilizados e comprometidos com a construção de uma nova relação homem-ambiente responsável, caracterizando-se por uma real mudança e não atividades dissociadas e esporádicas.

\section{Educação Ambiental: conceitos e classificações}

No cenário social vemos diversas ações voltadas para a preservação do planeta, liderados por Organizações não-governamentais (ONGs) e associações que procuram difundir a importância da mudança de comportamento do homem em relação ao planeta, mas assumem primordialmente o caráter de denúncia, ou seja, ações voltadas para a informação da população.

No âmbito da EA nas instituições de ensino, este foi sensivelmente difundido após a definição dos PCN's como tema transversal, atribuindo-lhe caráter de "pano de fundo" para o ensino curricular, que busca proporcionar a informação sobre a realidade, propondo discussões e ações pontuais sobre o tema, porém de forma descontinuada.

Nesse contexto, a prática em educação ambiental requer uma atividade pedagógica em três níveis distintos, conforme Vasconcellos, 2006: o nível informacional, que corresponde ao conhecimento cultural organizado e racional; o reflexivo crítico, o qual compreende a capacidade de ver e julgar, construindo um autoconhecimento e o da ação, visando a prática responsável e consciente, demonstrando consciência individual e social.

Ressalta-se, entretanto, a importância de cada um destes níveis para a sólida construção de uma educação ambiental que atenda o que a lei tão bem define, quando fala em processo de construção de valores, conhecimentos, habilidades individuais em prol da coletividade.

Para tanto, inicialmente, é preciso entender a percepção que o homem faz de si, de suas relações. Capra (2006) menciona que o reconhecimento de que é necessária uma profunda mudança de percepção e de pensamento para garantir a nossa sobrevivência ainda não atingiu a maioria dos líderes das nossas corporações, nem os administradores e professores das nossas grandes universidades.

É o nascimento de um novo paradigma que pode ser chamado de uma visão de mundo holístico, que concebe o mundo como um todo integrado. Pode também ser denominado visão ecológica, se o termo "ecológica" for empregado num sentido muito mais amplo e mais profundo que o usual. A percepção ecológica profunda reconhece a interdependência fundamental de todos os fenômenos, e o fato de que, enquanto indivíduos e sociedades, estamos todos encaixados nos processos cíclicos da natureza .

Ainda, como destaca Capra, os termos, "holístico" e "ecológico", diferem ligeiramente em 


\section{WERNZ et al., vol.(1), n¹, p. $35-45,2010$

ISSN:

seus significados e parece que "holístico" é um pouco menos apropriado para descrever o novo paradigma. Essa distinção entre "holístico" e "ecológico" é ainda mais importante quando falamos sobre sistemas vivos, para os quais as conexões com o meio ambiente são muito mais vitais.

Assim, temos a ecologia rasa que é antropocêntrica. Ela vê os seres humanos como situados acima ou fora da natureza, como a fonte de todos os valores, e atribui apenas um valor instrumental, ou de "uso", à natureza. A ecologia profunda não separa seres humanos - ou qualquer outra coisa - do meio ambiente natural. Ela vê o mundo não como uma coleção de objetos isolados, mas como uma rede de fenômenos que estão fundamentalmente ínterconectados e são ínterdependentes (Capra, 2006).

Desse modo, percebe-se a complexidade que envolve a tentativa de se conceituar a educação ambiental em toda a sua amplitude, enquanto processo educativo que precisa superar as limitações tradicionalmente atreladas a educação formal e também na educação informal.

Logo, a educação ambiental deve informar, confrontar e reconstruir os valores que alicerçam as relaçoes humanas com seu habitat.

Cultural e historicamente, a sociedade carrega uma percepção de que o homem é "senhor da terra" e como tal pode dispor de todos os bens que o ambiente possui sem sofrer as consequencias de seus atos.

Falar em percepção, também nos remete pensar sobre as diferenças sociais, culturais, educacionais e individuais de cada grupo social que através de ações demonstra sua construção a cerca do ambiente que o cerca, de modo a consolidar a sua relação de forma mais fragmentada ou mais holística.Entretanto, tudo isto nos faz retornar a idéia da complexidade que é conceituar educação ambiental, monstrando contudo que tal dificuldade, tal diversidade conceitual, pode contribuir para consolidar uma educação ambiental capaz de transpor amarras culturais e solidificar uma percepção mais globalizante.

A superação de visões fragmentadas do meio ambiente, constituem, certamente uma ponte para que se chegue mais próximo de uma EA que é complexa e desafiadora.

É neste contexto que se destaca os benefícios de uma diversidade conceitual à medida que esta sirva como propulsora do diálogo democrático e crítico a fim de confrontar as diferentes percepções sobre EA e a mutiplicidade de abordagens que permeiam a educação ambiental seja na esfera formal, como na informal, sem contudo deixar de construir um caminho para a transformação, para a superação de visões limitadoras para uma visão mais sistêmica, na qual o homem se perceba como parte integrante da natureza e não como seu ponto principal.

Por tudo isso, conceituar a educação ambiental significa buscar elementos para identificar, compreender as distintas percepções que compõem a historicidade do processo educativo ambiental, enquanto processo histórico-social que tem a figura humana, ora como vitima, ora como vilão, nesta relação que é irremediavelmente, interdependente.

Entende-se, portanto, que a compreensão dos diferentes conceitos de EA contribui para a reflexão crítica sobre este assunto, que é ponto importante na construção de um caminho rumo a uma EA transformadora e integradora para toda vida.

\section{Educação Ambiental nas escolas}

Primeiramente, é preciso deixar claro que a educação nas escolas, como fora delas, se dá através da mediação de indivíduos que trazem na sua bagagem teórica valores culturais familiares sobre a relação meio ambiente/homem, desta forma, organizaram a sua prática docente. Logo 
ensinarão termos técnicos e conceitos com o objetivo de conscientizar os alunos sobre a importância da preservação do meio ambiente para a sobrevivência humana.

Outro ponto importante é a compreensão da escola e toda sua comunidade docente. A educação ambiental deve fazer parte da vida escolar, não somente para cumprir com determinações legais, mas sim para ensinar que todos somos parte de um todo, que vivemos numa grande comunidade na qual a solidariedade é o caminho para a preservação, logo ninguém tem como direito destruir o meio ambiente.

Para tanto, pode-se basear no que diz os Parâmetros Curriculares Nacionais (PCNs) quando "afirmam ser a interdisciplinaridade essencial ao desenvolvimento de temas ligados ao Meio Ambiente, sendo necessário desfragmentar os conteúdos e reunir as informações dentro de um mesmo contexto, nas várias disciplinas". Narciso, $(2009$, p.88). O que significa dizer que a EA na escola deve ser trabalhada de forma transversal e não apenas em datas específicas ou em disciplinas afins, como ciências, biologia, geografia.

A educação escolar é a base para educação ambiental em sua essência. Ela servirá de disseminadora para os demais grupos da comunidade, da sociedade, ressaltando, assim, a importância de uma boa formação dos educadores, para que sejam verdadeiramente educadores ambientais e superem definitivamente a fragilidade que a educação ambiental atualmente apresenta, contribuindo para a construção de uma sociedade e equilibrada e ecologicamente responsável.

Conforme destacam Layrargues \& Loureiro (2009) apud JARDIM, p. 125): “A praticada pela escola e movimentos sociais e teorizada pela academia tem apresentado uma tendência progressiva a relacionar o espaço escolar com a vida comunitária, reconhecendo a dimensão social do ambiente e começando a abandonar o perfil conservacionista das décadas anteriores."

Desta forma, tem-se o início de uma mudança do paradigma ambiental superando uma visão meramente conservacionista e iniciando o caminho em direção a uma educação ambiental que supera o caráter de sensibilização, à medida que contribui para repensar os modelos sociais que geraram a crise ambiental.

Como destacam Rosa, et al. 2009, a base para que tal mudança aconteça é a efetivação da educação ambiental superando a perspectiva educacional tradicional, ou seja, faz-se necessário adotar metodologias que reflitam uma educação crítica e transformadora, com a proposta de repensar e reelaborar o saber. Logo, a realização da EA requer a utilização de novos métodos e práticas no sistema educacional, um currículo que possibilite a aquisição da identidade da escola e a valorização de educadores, além de uma abordagem metodológica que favoreça instauração de um diálogo crítico reflexivo.

A interdisciplinaridade é, portanto, essencial para a construção de um saber pedagógico, que não seja vazio de sentido, mas estimulador de uma prática que contribua para o equilíbrio do homem, da sociedade e do ambiente como um todo, num processo permanente.

Tem-se, o desafio para a escola, para os educadores: buscar através da educação ambiental valores individuais e coletivos, estimulando uma visão crítico-transformadora, que constrói saberes globais de forma interdisciplinar, culminando num cidadão que tem atitudes solidárias e assume seu papel enquanto parte e não como ser superior no ambiente planetário.

A educação ambiental não é um lócus seguro, um ponto de ancoragem que abriga e dá guarida à primeira vista; é um desassossego; é crise, resignificação de conhecimentos e de posturas diante da realidade (MOLON et al, 2009, p. 9).

Logo, falar de educação ambiental significa falar de busca, de caminho a ser percorrido, de processo que deve residir no fundamento de toda ação educativa. 


\section{Monografias Ambientais}

\section{METODOLOGIA}

O presente estudo foi desenvolvido com professores de duas escolas particulares do bairro Nossa Senhora das Dores de Santa Maria: Escola Moriah e colégio Coração de Maria, totalizando 10 professores que responderam ao questionário, de um universo de 15 profissionais que atuam no ensino fundamental destas escolas. Partindo da percepção de que a educação ambiental tem sido um tema crescentemente debatido como necessário para a construção de uma nova sociedade e, conseqüentemente, requerido nas escolas. Esta dimensão da educação passa por várias dificuldades de como compreendê-la e aplicá-la no processo educativo formal. Tendo como ponto de partida a análise da prática docente dos educadores de ensino fundamental, em relação à educação ambiental, pode-se refletir sobre a realidade da formação de professores; suas dificuldades, seus interesses, suas limitações e suas competências.

Para tanto, foi realizada uma pesquisa descritiva do tipo pesquisa de campo, onde os instrumentos de coleta de informações foram questionários abertos, entregues aos professores via coordenação com as seguintes questões:

- Como você entende a educação ambiental?

- Você trabalha educação ambiental com os alunos? Qual tempo você destina para este trabalho?

- Descreva as principais atividades que você utiliza para trabalhar educação ambiental?

- Quais são as maiores dificuldades no trabalho com educação ambiental?

- Como você avalia o(s) trabalho (s) desenvolvidos até o momento sobre educação ambiental?

- Onde você busca fundamentação teórica para o desenvolvimento do trabalho com EA?

- A EA está contemplada na proposta pedagógica da Escola?

As informações serviram de elementos comparativos para a pesquisa bibliográfica, a fim de iniciar um processo de conhecimento e discussão sobre a realidade da importância da EA na atuação de alguns dos educadores do ensino fundamental, como amostra deste processo.

\section{RESULTADOS E DISCUSSÃO}

\section{Análise quantitativa das respostas do questionário}

\section{Como você entende a educação ambiental?}

Sobre o entendimento de educação ambiental, 70\% dos educadores, entendem a educação ambiental como conscientização sobre preservação do meio ambiente enquanto espaço mais ecológico do que eco-socio-político. Que vai desde a preservação da Flora-Fauna até o constante ensinar e aprender sobre os diferentes ambientes. Envolve as noções de cuidado, preservação até o respeito cotidiano e individual pelo cidadão. 30\% entendem a EA como aprendizagem em relação ao que pode ou não ser feito pelo homem para respeitar o meio ambiente.

\section{Você trabalha educação ambiental com os alunos? Qual tempo você destina para este trabalho?}

A análise das respostas aponta que $100 \%$ dos educadores pesquisados trabalham com EA; em relação ao tempo destinado a este trabalho, 30\% destacaram que trabalham especificamente durante as várias disciplinas (especialmente de ciências e geografia), até mesmo de religião; $A$ freqüência da abordagem da EA varia desde momentos especiais até de forma contínua, conforme 


\section{Monografias Ambientais}

a oportunidade, ou de forma constante. $70 \%$ indicam número de vezes, dias, momentos ou disciplinas semanais relacionadas, desde 1 vez até quatro vezes por semana. $40 \%$ afirmam trabalhar quatro vezes ou menos na semana e $50 \%$ desenvolvem o tema conforme os temas que estão sendo desenvolvidos, sem definir tempo exato para tanto. $20 \%$ indicam todos os dias ou de forma contínua.

\section{Descreva as principais atividades que você utiliza para trabalhar educação ambiental?}

$100 \%$ responderam que trabalham EA no seu cotidiano; as respostas envolvem variadas formas de inclusão na atividade didática dos professores: projetos, pesquisas, produções da mídia impressa e de vídeo, construções artístico-artesanais, decoração, reciclagem, plantio de hortas e mudas de árvores e paisagismo, reflexões a partir de textos do cotidiano.

\section{Quais são as maiores dificuldades no trabalho com educação ambiental?}

$90 \%$ dos educadores entendem que a maior dificuldade é conscientizar os alunos e as famílias que é preciso mudar as atitudes e 10\% disseram não encontrar dificuldades.

\section{Como você avalia o(s) trabalho(s) desenvolvidos até o momento sobre educação ambiental?}

$100 \%$ dos educadores consideram o trabalho desenvolvido em EA bom ou satisfatório, ressaltando que os alunos sempre apresentam alguma mudança de comportamento em relação ao meio ambiente.

\section{Onde você busca fundamentação teórica para o desenvolvimento do trabalho com EA?}

$90 \%$ dos professores buscam sua fundamentação em revistas, jornais, livros e internet e $10 \%$ buscam sua fundamentação em livros e na proposta da escola.

\section{A EA está contemplada na proposta pedagógica da Escola?}

Neste caso, 90\% dos educadores afirmam que a Educação Ambiental é contemplada na proposta pedagógica da sua escola e $10 \%$ responderam que a EA está presente na escola através de projetos específicos (datas especiais).

A partir das questões e respostas apresentadas, é pertinente retomarmos alguns pontos interessantes. A educação ambiental é percebida na sua maioria como tomada de consciência sobre os cuidados que cada um deve ter com o meio ambiente, indicando o que pode e deve ser feito. Há uma visão excessivamente ecológica, redutora da relação do homem com os elementos concretos do seu ambiente, como guardião da integridade ecológica destes elementos naturais ou concedidos por Deus. Uma visão quase antropocêntrica na qual o homem ainda é a parte mais importante nesta relação unilateral.

Não cabe aqui criticar, mas sim ressaltar que a visão que os educadores trazem é construída a partir de tais concepções, as quais organizarão seus trabalhos educativos e servem de exemplo para seus alunos. Por isso, o tempo destinado para trabalhar com Educação ambiental é ainda bem limitado, haja vista, que a limitação disciplinar é evidente, além disso, as limitações individuais, e as limitações educativas dificultam a mudança.

Trabalha-se com educação ambiental sem uma continuidade reflexiva essencial para ir além da conscientização chegando até a mudança de comportamento em relação ao homem e a natureza. 
ISSN:

Reflexo também da falta de formação adequada na área, pois sabe se que os cursos de licenciatura não oportunizam disciplinas que contemplem a EA, embora o tema seja considerado de grande importância na sociedade. Esse fato produz uma enorme lacuna nos discursos feitos pelos professores.

Em relação às atividades realizadas, é forte o trabalho com temas bem pontuais como lixo, paisagismo (plantio de mudas ornamentais), horta e também com pesquisas e a interpretação de textos.

Pode-se perceber, portanto, que o trabalho realizado nas escolas ainda é muito voltado para conscientização relacionada aos problemas cotidianos, os quais fazem parte dos discursos mais divulgados na mídia e por educadores de modo geral.

Não se trata de condenar as atividades realizadas, mas sim de chamar atenção para a complexidade para as questões ambientais, envolvendo a problematização das formas de posicionar-se sobre e perceber o mundo arraigadas na fala, na cultura e na condução do trabalho do professor.

Atividades essas que não têm a fundamentação necessária para contribuir com a modificação da visão culturalmente difundida na sociedade capitalista e globalizada.

Assim, "O professor tem uma compreensão crítica da educação e da educação Ambiental. Contudo, as situações de aprendizagem relacionadas com a temática ambiental acabam mantendo suas bases fixadas no modelo tradicional de educação" (CHAVES e FARIAS, 2005, p. 67).

Dessa forma, as atividades realizadas, deixam de serem propulsoras de mudanças comportamentais, pois esta desarticulação entre as disciplinas e o contexto escolar de modo geral conduz os alunos a um primeiro estágio: o da informação, que necessita ser alimentado com atividades desafiadoras que os façam repensar seus conceitos sobre o meio ambiente e suas relações coletivas.

Desse modo, o conscientizar os alunos e familiares sobre as questões ambientais é entendido pelos professores como a maior dificuldade quando se trabalha com educação ambiental. Cabe ressaltar o que já se comentou sobre a importância de cada professor reconhecer a sua percepção a cerca da relação homem/ambiente buscando, a partir de então, verificar a percepção de seus alunos, da comunidade escolar, para proporcionar uma reflexão que vá além de atividades específicas, como plantar uma horta, ou fazer a separação dos resíduos sólidos; ao contrário que seja uma reflexão que ajude a construir um caminho de mudança para a crise ambiental e de relações que a comunidade global enfrenta.

A conscientização é um processo lento e gradual, que começa com a informação, passa pela reflexão, pela discussão, pelo confronto de idéias, para então produzir uma nova visão e uma nova conduta.

Ao mesmo tempo em que os professores entendem a conscientização como a maior dificuldade, concluem que todo trabalho sempre produz algum resultado nos seus alunos, embora este resultado ainda seja muito pequeno se comparado com a crise na qual se está inserido.

Esse fato reflete a forma como os professores buscam as informações para trabalhar com educação ambiental. Sabe-se que este não foi um tema aprofundado nas suas trajetórias de formação e que em alguns casos, pode-se dizer que sequer foi trabalhado. Daí a escolha de elementos didáticos que tratam a questão com uma visão imediatista e na maioria antropocêntrica, onde as questões ambientais aparecem muito como forma de denúncia.

De acordo com o questionário aplicado, nenhum dos professores pesquisados procurou qualificar-se em educação ambiental através de cursos, buscando uma formação mais profunda do tema para poder transformar informações em um discurso que toque, que inicialmente sensibilize 
para a problemática ambiental, mas que não fique somente neste discurso e vá além, plantando sementes para a consolidação de uma nova cultura ambiental, baseada na solidariedade, no respeito coletivo com um todo, a qualquer tipo de vida, respeitando a interdependência existente e ao mesmo tempo compreendendo as diferenças de cada parte.

Essa situação pode ser interpretada como algumas escolas ainda tratam a questão ambiental, embora na maioria o tema já faça parte da proposta pedagógica. Em algumas ela ainda é lembrados de forma pontual em projetos específicos e limitados, ou seja, contribui para que os professores trabalhem da forma como relatam na questão dois, de forma limitada, em momentos e/ou em disciplinas específicas, sem uma continuidade.

A visão apresentada pela amostra pesquisada de docentes reflete o tratamento e a preocupação dos professores em relação à educação ambiental. Essa é tratada pelo grupo de professores pesquisados, de forma ainda muito o inconsistente é trabalhada, mas a sua essência precisa ser revista, repensada, reorganizada, para que possa ser efetiva, rompendo com visões historicamente limitadas e sem resultados significativos para as comunidades e para a sociedade

A educação ambiental está presente nas escolas, mas a sua percepção como educação precisa ser reconstruída, a partir da valorização de todas as dimensões que compõem a concepção de EA que cada educador, que cada escola fundamenta sua forma de agir.

Desse modo, a educação ambiental nas escolas, sejam elas particulares ou públicas, já está incorporada como temática do processo educativo formal, mas assim como outras temáticas absorvidas pela escola conduz-se de forma externa, ou seja, é reflexo das demandas sócias e não tema legítimo da educação escolar enquanto instrumento essencial na formação de um cidadão que supera paradigmas educativos e incorporando a EA como objeto da educação.

\section{CONCLUSÃO}

A realidade vivida pela sociedade atual juntamente com toda carga de informações e formas de acesso ao conhecimento trazido pela análise da história da humanidade, da sua trajetória científica, antropológica, filosófica e sociológica, apontam para a necessidade de se discutir, de se repensar a relação do homem com seu planeta, indicando a urgência de uma modificação profunda e ampla neste processo.

É neste cenário de crise, de grandes catástrofes, que a problemática ambiental ganha importância crucial, e nesse contexto, tem importante participação da educação ambiental. Que ao assumir-se como educação, como processo contínuo de construção e reconstrução do sujeito humano, coloca-se diante de um grande desafio ao desejar educar para o campo ambiental.

Dentro dessa perspectiva, a escola e os educadores assumem papel de suma importância, pois através de sua prática, contribuirão ou não, para a formação ambiental da comunidade discente. Ao mesmo tempo em que reconstroem seus saberes na esfera ambiental, à medida que estabelecem uma relação de diálogo sobre estas questões.

A partir da pesquisa realizada, foi possível constatar que a educação é tema presente na prática docente. O tema ainda é tratado de forma pontual, sendo desenvolvido em momentos específicos, ficando muitas vezes limitado as datas específicas e quando os temas a serem desenvolvidos permitem a inserção desta temática. Mesmo existindo uma legislação e PCN's que apresentam a EA como tema transversal, ainda não se chegou à prática este entendimento.

Como ponto negativo destaca-se a necessidade da EA ser compreendida como tema realmente transversal, que permeia a prática educativa, como elemento estimulador de uma nova 


\section{WERNZ et al., vol.(1), n¹, p. $35-45,2010$

visão da relação homem/planeta. Aqui se pode vislumbrar o desafio que a escola, enquanto instituição social com a função contribuir para a construção de uma sociedade responsável e ética, que deve ter em seus educadores como motivadores para novas percepções do indivíduo inserido na coletividade.

Não basta, portanto, uma educação ambiental presente na legislação. Esta deve ser desenvolvida nas escolas de forma transversal. É indispensável que ela faça parte da formação dos educadores, especialmente do currículo das licenciaturas, que têm a responsabilidade inserir no mercado profissionais que contribuam para formação dos cidadãos. Destacando, que este educador ambiental é sujeito "aprendente", ou seja, é agente da sua formação, mas que precisa ter acesso a conhecimentos científicos para reconstruir seus saberes de forma a flexibilizá-los e adequá-los as necessidades contemporâneas.

Entendo que este seja o ponto de partida para que se rompa com os paradigmas que mantém a situação ambiental no patamar atual.

Por tudo isso, sugere-se a construção de curso para educadores, em especial, do ensino fundamental, com vistas a subsidiar a formação destes para o exercício da educação ambiental. Formação esta, que deve ser sólida, mas ao mesmo templo flexível para formular e reformular as dificuldades que surgem, superando as limitações do trabalho realizado nas escolas. Um curso que possibilite a reconstrução dos saberes dos educadores em relação às questões ambientais e os conduza a desenvolver sua prática educativa de modo a promover uma visão integradora e comprometida com a solidariedade efetiva e não apenas teórica.

Enfim, a educação ambiental, na prática docente, é de suma importância para vislumbrarem-se possibilidades de transformação e de superação da crise vigente, precisa de profissionais bem preparados teórica e metodologicamente para atuarem como educadores ambientais, logo, este é o primeiro desafio a ser vencido nesta caminhada, que é contínua. Nesse processo, a formação dos educadores que atuarão nas instituições de ensino formal assume papel crucial, quando se tem na EA a esperança, as possibilidades de construir uma sociedade mais solidária, mais consciente das suas responsabilidades e mais atuante.

\section{REFERÊNCIAS BIBLIOGRÁFICAS}

ARAúJo, Thiago Cássio d' Ávila. Principais marcos históricos mundiais da educação ambiental. Ambiente Brasil. 2007. Disponível em http://noticias.ambientebrasil.com.br/noticia/?id=33350. Acesso em janeiro 2010.

BIGLIARDI, Rosane Vinhas; CRUZ, Ricardo Gauterio. O papel da educação ambiental frente à crise civilizatória atual. Ambiente \& Educação, v. 12, p.127-141, 2007.

BONOTTO, Dalva Maria Bianchini. Formação docente em educação ambiental utilizando técnicas projetivas. Paidéia, 2005, 15(32), 433-440.

CAPRA, Fritijof. A teia da vida: uma nova compreensão científica dos sistemas vivos. Tradução Newton Robertal Eichemberg .2006. Editora Cultrix: São Paulo.

COSTA, Ronaldo Gonçalves de Andrade. Um olhar crítico sobre a educação ambiental na formação de professores em uma instituição de ensino superior gaúcha. Revista Eletrônica do Mestrado em Educação Ambiental. ISSN 1517-1256, v. 22, janeiro a julho de 2009. Disponível em: http://www.remea.furg.br/indvol23.php. Acesso em dezembro 2009.

CHAVES, André Loureiro; FARIAS, Maria Eloísa. Meio ambiente, escola e a formação dos professores. Ciência e Educação, v.11, n. 1, p. 63-71, 2005.

GONÇALVES, Rita de Athayde; VIERO, Lia Margot Dornelles; ORTIZ, Ail Conceição Meireles. Org. Desafios da educação na sociedade de consumo. Santa Maria: Centro Universitário Franciscano, 2007. 
GUIMARÃES, Mauro. A formação de educadores ambientais. Campinas: Papirus, 2004.

ISAIA, Enise Maria Bezzerra Ito. Org. Reflexões e práticas para desenvolver Educação Ambiental na escola. Santa Maria: Ed. IBAMA, 2000.

JACOBI, Pedro. Educação ambiental cidadania e sustentabilidade. São Paulo: Cadernos de pesquisa, n. 118, p.189-205, março 2005.

JARDIM, Daniele Barros. Educação ambiental: trajetórias, fundamentos e identidades. Revista Eletrônica do Mestrado em Educação Ambiental. ISSN 1517-1256, v. 22, janeiro a julho de 2009, p. 120-130. Disponível em:

LEl 9795/99. Disponível: http://www.lei.adv.br/9795.htm Acesso em dez. 2009.

MERCK, Ana Maria Thielen. 2009. A percepção ambiental. Dispositivo, color.

MMA. Encontros e caminhos: formação de educadoras (es) ambientais e coletivos educadores. Brasília: Edições MMA, 2005. . Identidade da educação ambiental brasileira. Brasília: Edições MMA, 2004.

MIRANDA, Daniela Janaína Pereira. Educação e percepção ambiental: o despertar consciente do saber ambiental para a ação do homem na natureza. Revista Eletrônica do Mestrado em Educação Ambiental. ISSN 1517-1256, v. 19, julho a dezembro de 2007. Disponível em: http://www.remea.furg.br. Acesso em janeiro 2010.

MOLON, Susana Inês; ARRUDA, Rogério Dias de; PAREDES, Joaquim. A formação em educação ambiental e as TICs:um olhar sobre aPPGEA/FURG- Brasil. 2009. Revista/Libro: Didácticas específicas.Revista eletrônica n.0. Disponível em: http://www.didacticasespecificas.com. Acesso em: dez 2009.

NARCIZO, Kaliane Roberta dos Santos. Uma análise sobre a importância de trabalhar educação ambiental nas escolas. Revista Eletrônica do Mestrado em Educação Ambiental.ISSN 1517-1256, v. 22, janeiro a julho de 2009. Disponível em: http://www.remea.furg.br. Acesso em novembro 2009.

PICCININI, Cláudia Lino. Educadores ambientais: refletindo sobre a ação na modernidade tardia. Ambiente \& Educação, v. 11, p.113- 126, 2006.

ROSA, Luciene Gonçalves; SILVA, Monica Maria Pereira da; LEITE, Valderi Duarte. Educação ambiental em uma escola de formação inicial de nível médio: estratégias e desafios do processo de sensibilização. Revista Eletrônica do Mestrado em Educação Ambiental. ISSN 1517-1256, v. 22, janeiro a julho, p. 454475, 2009. Disponível em: http://www.remea.furg.br. Acesso em novembro 2009.

SAUVÉ, Lucie. Educação ambiental: possibilidades e limitações. Educação e pesquisa, São Paulo, v.31, n.2, p.317-322, maio/ago. 2005.

SILVA, Monica Maria Pereira; LEITE, Valderi Duarte Leite. Estratégias metodológicas para formação de educadores ambientais do ensino fundamental. XXVII Congresso Interamericano de Engenharia Sanitária e Ambiental. Disponível em http://www.bvsde.paho.org/bvsaidis/impactos/vi-041.pdf. Acesso em: 10 de jan. 2009.

TRIGUEIRO, André. Org. Meio ambiente no século 21: 21 especialistas falam da questão ambiental nas suas áreas de conhecimento. Rio de Janeiro: Sextante, 2003.

TRISTÃO, Martha. Tecendo os fios da educação ambiental: o subjetivo e o coletivo, o pensado e o vivido. Educação e Pesquisa, São Paulo, v. 31, n. 2 , p. 252 - 264, maio/ago.2005

UNESCO. Educação ambiental - As grandes orientações da Conferência de Tbilisti. Coleção Meio Ambiente. Série Estudos: Educação Ambiental, Edição Especial, Ed. IBAMA, Brasília, 1997. 154 p.

Pensar o Ambiente: bases filosóficas para Educação Ambiental. Organização: Isabel Cristina Moura de Carvalho; Mauro Grün; Rachel Trajber. Brasília: Ministério da Educação da Educação, Secretaria de Educação Continuada, Alfabetização e Diversidade, 2007.

VASCONCELLOS, Hedy S.R. ; PICCININI, C. L. ; SÁNCHEZ,C. . A formação do educador ambiental: reflexões sobre os caminhos para a construção e delimitação de um objeto de pesquisa em Educação Ambiental. In: 29 Reunião Anual da ANPED, 2006, Caxambu. 29a Reunião Anual da ANPED Educação, Cultura e Conhecimento na contemporaneidade: desafios e compromisso, 2006. 